\title{
The Effect of Family-Centered Empowerment Model on Quality of Life Among Mothers of Asthmatic Children
}

\author{
Raheleh Rajabi, ${ }^{1}$ Gholamhossein Mahmoudirad, ${ }^{2}$ Sayedeh Sakineh Sabzevari, ${ }^{3}$ Fariba Borhani, ${ }^{4}$ Ellnaz \\ Yazdanparast, ${ }^{1}$ and Motahareh Faramarzpor ${ }^{5,}$ \\ ${ }^{1}$ Department of Nursing, Faculty of Ferdows Paramedical, Birjand University of Medical Sciences, Birjand, IR Iran \\ ${ }^{2}$ Health Qualitative Research Center, Birjand University of Medical Sciences, Birjand, IR Iran \\ ${ }^{3}$ Department of Medical Surgical, Razi School of Nursing and Midwifery, Kerman University of Medical Sciences, Kerman, IR Iran \\ ${ }^{4}$ Medical Ethics and Law Research Center, Shahid Beheshti University of Medical Sciences, Tehran, IR Iran \\ ${ }^{5}$ Department of Nursing, Bam University of Medical Sciences, Bam, IR Iran \\ "Corresponding author: Motahareh Faramarzpor, Department of Nursing, Bam University of Medical Sciences, Bam, IR Iran. Tel: +98-3444216064, E-mail: \\ mfaramarzpor61@gmail.com
}

Received 2015 July 9; Revised 2015 November 23; Accepted 2015 December 16.

\begin{abstract}
Background: Asthma causes different physical, emotional, and social limitations for the afflicted children and their families and reduces their quality of life. Therefore, the quality of life in families, particularly in mothers, needs to be enhanced through strategies such as empowerment.

Objectives: The aim of this study was to assess the effect of the Family-Centered Empowerment Model on quality of life among the mothers of asthmatic children.

Methods: A convenience sample of 172 mothers was recruited for this quasi-experimental study. Mothers were alternately allocated either to a control group or an experimental group based on the day in which they referred to the study setting. Accordingly, mothers who referred to the setting in odd and even days of a weak were allocated respectively to the control and experimental groups. A demographic questionnaire and the pediatric asthma caregiver's quality of life questionnaire (PACQLQ) were used for data collection. The validity of the questionnaire was confirmed by a panel of experts (relevance: 0.98; clarity: 0.96; and simplicity: 0.94) while its reliability was confirmed by a Cronbach's alpha of 0.88 . A four-step empowerment program was implemented for the mothers in the experimental group based on the Family-Centered Empowerment Model. The four steps included knowledge improvement, self-efficacy, self-esteem, and evaluation. Mothers in the control group received no intervention during the study. Before and after the intervention, the mothers in both groups were asked to complete the study questionnaires. The data were described and analyzed by using descriptive and inferential statistics.

Results: There were no significant between-group differences regarding the mothers' demographic characteristics and their baseline quality of life scores. However, after the intervention, the scores of quality of life and its physical limitation and emotional function domains were significantly lower in the experimental group, denoting higher quality of life $(\mathrm{P}<0.001)$.

Conclusions: The Family-Centered Empowerment Model significantly improves quality of life among the mothers of children who suffer from asthma. Given the important role of mothers in giving care to their ill children, nurses are recommended to use the model to encourage mothers' active participation in care giving to their children.
\end{abstract}

Keywords: Family-Centered Empowerment Model, Quality of Life, Asthma, Mothers

\section{Background}

Asthma is a chronic inflammatory disease of the airways which is associated with diffuse airway narrowing. The prevalence of asthma in Iran is higher than the mean global prevalence rate probably due to factors such as progressive urbanization and industrialization, specific climate conditions, as well as the air and environmental pollutions (1).

Asthma is the most common chronic illness in the childhood population and the first leading cause of hospital admission and absence from school. In some countries, the prevalence of asthma has increased by 50\% (2). Asthma can cause different physical, emotional, and social limitations for the afflicted children and their families. If the symptoms are not controllable, limitations are aggravated and thus, patients become more dependent on others. On the other hand, asthma and its associated disability significantly affect the functions of families and involve them in many tasks, responsibilities, and concerns regard-

Copyright ( ) 2016, Birjand University of Medical Sciences. This is an open-access article distributed under the terms of the Creative Commons Attribution-NonCommercial 4.0 International License (http://creativecommons.org/licenses/by-nc/4.0/) which permits copy and redistribute the material just in noncommercial usages, provided the original work is properly cited. 
ing patient care, medical and educational services, healthcare costs, uncertain future, social isolation, and loss of social opportunities (3).

Absence from school and work as well as asthmarelated financial, physical, and emotional problems significantly affect afflicted children and their families' quality of life (QOL). Therefore, the most important issue regarding asthma is QOL (4). QOL is defined as the substantial impacts of an illness and its treatment outcomes on patients as perceived and verbalized by them. QOL is affected by physical, spiritual, psychological, financial, and social aspects of life as well as the health, work, and family conditions. These aspects and conditions can be discussed independently, even though there are interactions among them (4). Mothers are the main family caregivers of the children who suffer from asthma; therefore, heavy carerelated responsibilities, poor preparation for care giving, and lack of high quality educational services undermine mothers' physical and emotional health (5). They may feel worthless and guilty, experience high levels of stress, and suffer from low mental health and QOL (6). Moreover, due to its chronic nature, asthma affects parents' mental health and reduces their QOL (7).

Walker et al. (2008) found that parents' low QOL was significantly correlated with their children's absence from work and school, activity limitations, inadequate sleep, frequent nighttime awakenings, and poor psychological health (8). Empirical evidence shows that giving care to the children who suffer from chronic illnesses takes too much time and energy from the parents and hence, parents are compelled to allocate inadequate time to themselves and consequently suffer from poor QOL (9). One of the factors contributing to children's QOL is their parents' health status which in turn is affected by the workload of care giving. The care-related requests of ill children can reduce their own and their family caregivers' QOL (10).

The QOL in caregivers of ill children is also affected by their frequent absence from work, financial strains, stress, health-related beliefs, perceived barriers to care giving, psychological issues, adaptive styles, and family, environmental, and social factors (11). Affliction by chronic illnesses can affect patients' interactions with their immediate physical and social environments and cause them different problems. At the same time, using preventive strategies can help prevent the incidence of $70 \%$ of acute episodes of such illnesses. One of the preventive strategies is patient education which not only helps control the underlying illness, but also can improve QOL (12). However, pediatricians do not regularly provide families with asthma-related educations due to reasons such as limited patient-doctor visitation time as well as serious concerns, anxiety, discomfort, and confusion among ill children and their families (13).

Poor treatment outcomes among asthmatic children necessitate different educational interventions in order to improve the quality of treatments (14). One of the strategies to improve health, knowledge, awareness, and QOL is to empower children and their families in order to effectively cope with the consequences and the complications of their illnesses and manage their illnesses and lives. Without empowerment, patients and families cannot reduce perceived barriers to their health promotion. Consequently, one of the aims of care services should be to improve the QOL of families, particularly mothers, through empowerment (13). Empowerment is a dynamic, positive, interactive, and social process which takes place in the interaction with others and helps patients feel greater responsibility to their health, interact with healthcare authorities more effectively, feel greater satisfaction, show better responses to treatments, avoid complications of illness, reduce their costs in healthcare, adopt a more positive attitude toward their problems, and have a higher QOL (15).

The aim of family-centered empowerment is to improve children's health, manage their illnesses, reduce the incidence of the acute episodes of their illnesses, and improve QOL in the afflicted children and their parents through helping families provide higher quality care. Families of children afflicted by asthma suffer from poor QOL (16). Moreover, these children are greatly dependent on their parents while the quality of care provided to them is directly correlated with their parents' well-being and health. Consequently, it is important to pay careful attention to parents' well-being and QOL during the process of care delivery (15). On the other hand, maternal health is the cornerstone of family and community health and hence, paying special attention to mothers' health and improving their QOL are matters of great importance. Besides the QOL of chronically-ill children and adolescents, the QOL of their mothers has also received special attentions in recent years (17).

Kerman is an industrial city in Iran. The level of industrial pollution in the city is rather high. Therefore, the prevalence of asthma is expected to be high in the city. Nonetheless, we found that no education is provided for asthmatic patients and their mothers who refer to the asthma and allergy clinic of the city. Therefore, implementing an educational intervention for this group of clients seemed to be essential.

According to Anderson and Funnell (2000), patient education by using traditional teaching methods is not significantly effective in changing patients' lifestyles or promoting their engagement in self-care activities (18). Welch and Austin (2001) also noted that educations should be 
provided by using interactive teaching methods (19). One of the strategies to achieve this aim is to empower mothers to manage problems and complications associated with their children's asthma and achieve a higher QOL. The results of our literature review illustrated that the effects of the Family-Centered Empowerment Model (FCEM) have not yet been assessed on the QOL of the mothers of children who suffer from asthma in Kerman, Iran. Therefore, we conducted this study to assess the effects of the FCEM on QOL among the mothers of asthmatic children. In order to empower families, we used the components of the FCEM such as enhancement of knowledge, self-esteem, selfefficacy, and self-control. These strategies helped the participating mothers actively take part in care giving to their children, control their children' illnesses, and respond to their children's health-related needs more efficiently.

\section{Methods}

This quasi-experimental study was undertaken in 2011 in the asthma and allergy clinic of Afzalipour hospital, Kerman, Iran. The sample size was determined by using the sample size calculation formula for comparing two means with type I and II errors of 0.05 and 0.10 , respectively. A significant difference of 0.2 of standard deviation between the experimental and the control groups regarding the improvement in the QOL score was also designated in the calculations. Consequently, it was revealed that 86 mothers were needed for each group. Therefore, 172 mothers of the school-age children who suffered from asthma were conveniently recruited to the study and alternately allocated to the study groups. Allocation to either group was performed based on the day (even or odd) in which mothers referred to the study setting. In the study setting, asthma and allergy specialists visited children only on Sundays and Mondays. Therefore, mothers who referred to the clinic on Sundays and Mondays were allocated respectively to the control and experimental groups.

After obtaining necessary permissions form the administrators of the hospital, we referred to the clinic, got familiar with its administrators, and started to recruit mothers to the study. Mothers with the following criteria took part in the study: having a 6 - 12 year-old child with a confirmed diagnosis of asthma for at least three months, being able to read and write Persian, and suffering from no mental disorder. The participants were informed about the aim of the study, the voluntariness of participation in or withdrawal from the study, and the confidential management of their data. Verbal and written consent were also obtained from the mothers before data collection.

The study instruments were a demographic questionnaire and the pediatric asthma caregiver's quality of life questionnaire (PACQLQ). The PACQLQ contains thirteen items falling into the two domains of activity limitation (four items) and emotional function (nine items). The items are responded on a five-point scale, in which response options ranged from 5 (most severe impairment) to 1 (no impairment). The scores of the items are summed to obtain the total score of the PACQLQ. Lower scores show higher QOL and vice versa. The validity of the questionnaire was confirmed through seeking comments from ten members of nursing and medical faculty. The Cronbach's alpha values of the PACQLQ and its activity limitation and emotional function domains were $0.88,0.92$, and 0.84 , respectively.

The collected data were entered into the SPSS software (version 16.0). The homogeneity of the groups in terms of the participants' demographic characteristics and baseline QOL scores was assessed through the independentsample t-test, Chi-square test, and Fisher's exact test. Then, baseline analyses were performed in order to identify the mothers' empowerment-related needs. Finally, a needbased empowerment program was developed based on the FCEM.

In order to implement the developed program, a stepby-step approach was employed. The four steps of the approach included knowledge improvement, self-efficacy, self-esteem, and evaluation.

The first step of our FCEM-based empowerment program was to enhance threat perception of the empowered agent, i.e. the system of family, which consisted of mothers and other family members. In this step, mothers were considered as main caregivers and hence, they filled out the study questionnaires. Our primary analyses revealed that mothers were not sufficiently sensitive to their children's conditions and problems. Thus, several educational sessions were held to enhance their threat perception through expanding their knowledge about asthma and its treatment. The education was provided through group discussion, lecture, question-and-answer, PowerPoint presentation, and booklets. The contents of the sessions were mainly about the nature of asthma, its symptoms, complications, and prognosis, aggravating and alleviating factors, medication use, management of acute episodes of asthma, and the role of nutrition in the recurrence of asthma.

In the second step of the FCEM-based program, i.e. the problem-solving step, the role playing and group discussion methods were used to give mothers positive feelings about their abilities, enhance their self-efficacy, self-esteem, and self-control, and improve their problemsolving ability. During role playing, mothers were practically encountered with a problem and got involved in solving it though developing different solutions to the prob- 
lem and selecting the best one. Accordingly, they were divided into small 3 - 5-person groups. Then, four 45 - 60minute sessions were held for each group during which, mothers went through the problem-solving process. In the sessions, mothers discussed their own problems and their strategies to solve them. Moreover, they attempted to show the strategies which they used to manage their children's health problems by using a mannequin. The strategies included positioning, use of spray and spacer, and administration of other medications. All the skills were primarily trained to the mothers by the first author of the current paper and then, mothers were allowed to exercise the trained skills. The first author supervised the mothers in this step until they achieved mastery over the skills.

In the educational partnership step, educational materials were printed on cards, and mothers were asked to distribute the cards among their family members in order to enhance their participation in patient care process. Mothers were asked to train other family members about patient care in order to enable them to give care to ill children in their absence. Moreover, training provided to fathers by mothers helped fathers understand the importance of taking children to hospital, procuring medications and healthy foods, creating an allergen-free environment, keeping no pet, and avoiding smoking at home, and taking greater responsibility towards their children's health.

The fourth step of the FCEM-based program was evaluation. Formative evaluations were performed at the beginning of each session in order to evaluate mothers and their family members' knowledge and self-efficacy. Such evaluations were performed by using techniques such as group discussion and question-and-answer. Moreover, summative evaluation was performed one month after the study intervention through asking the mothers to recomplete the PACQLQ. On the other hand, mothers in the control group received no educational intervention during the study. However, for the sake of research ethics, educations already provided to the mothers in the experimental group were also provided to the mothers in the control group in a single educational session held after doing the posttest, i.e. one month after the intervention. Moreover, a booklet, containing the education contents, was provided to the mothers in the control group.

The present study was approved by the ethics committee of the research and technology administration of Kerman University of Medical Sciences, Kerman, Iran. The data were analyzed by doing the independent- and pairedsample t-test, Chi-square test, and Fisher's exact test at a confidence level of higher than 0.95.

\section{Results}

The results of the Chi-square and Fisher's exact tests revealed no significant between-group differences regarding mothers' age, employment and educational status, place of residence, and smoking (Table 1). The means of mothers' age in the experimental and control groups were $33.44 \pm 6.69$ and $32.72 \pm 5.75$, respectively $(\mathrm{P}>0.05)$. The independent-sample t-test showed that at baseline, there were no significant differences between the groups in terms of QOL scores in the two dimensions of activity limitation and emotional function. However, after the intervention, the between-group differences regarding the mean scores of these two dimensions were statistically significant $(\mathrm{P}<0.05$; Table 2$)$.

The paired-sample t-test also showed that in the experimental group, there were significant differences between the baseline and the posttest values of QOL scores in both dimensions of PACQLQ $(\mathrm{P}<0.05)$ while in the control group, these pretest-posttest differences were not statistically significant $(\mathrm{P}>0.05)$. Moreover, the results of the independent-sample t-test illustrated a significant difference between the groups in terms of the pretest-posttest mean difference of QOL scores in both dimensions of the PACQLQ $(\mathrm{P}<0.05$; Table 3).

\section{Discussion}

Uncontrolled asthma has considerable effects on the efficiency and QOL of family caregivers. Family caregivers of asthmatic children experience many limitations in doing activities of daily living and suffer from continuous anxiety and emotional tensions. Thus, their QOL is significantly affected (3).

The results of the present study showed that the FCEM significantly improved the QOL of the mothers of asthmatic children in both dimensions of QOL namely activity limitation and emotional function. This is in agreement with the findings of a study conducted by Teimouri et al. (2014) who investigated the effects of the FCEM on the QOL of the mothers of asthmatic children in Tehran, Iran. Their findings showed the effectiveness of the FCEM in the significant improvement of mothers' QOL (2).

We also found a significant difference between the groups regarding the pretest-posttest mean difference of both dimensions of QOL, denoting a significant improvement in the QOL of the mothers in the experimental group. This finding can be related to the interest of parents, particularly mothers, in learning and engaging in patient care. Mothers of asthmatic children are involved in care giving to patients who suffer from a chronic condition. Therefore, 
Table 1. The Frequency Distribution of the Participants' Demographic Characteristics ${ }^{\mathrm{a}}$

\begin{tabular}{|c|c|c|c|c|}
\hline \multirow[t]{2}{*}{ Variables } & & \multicolumn{2}{|c|}{ Groups } & \multirow[t]{2}{*}{ P Value (The Chi-Square Test) } \\
\hline & & Experimental & Control & \\
\hline \multirow{3}{*}{ Age, $y$} & $20-30$ & $33(38.4)$ & $40(46.5)$ & \multirow{3}{*}{0.52} \\
\hline & $31-40$ & $43(50)$ & $36(41.9)$ & \\
\hline & $41-55$ & $10(11.6)$ & $10(11.6)$ & \\
\hline Employment & Employed & $21(24.4)$ & $17(19.8)$ & 0.46 \\
\hline \multirow{3}{*}{ Education } & Below-diploma & $13(15.1)$ & $14(16.3)$ & \multirow{3}{*}{0.8} \\
\hline & Diploma & $45(52.3)$ & $48(55.8)$ & \\
\hline & Higher than diploma & $28(32.6)$ & $24(27.9)$ & \\
\hline \multirow{2}{*}{ Place of residence } & Urban areas & $77(89.5)$ & $72(83.7)$ & \multirow{2}{*}{0.26} \\
\hline & Rural areas & $9(10.5)$ & $14(16.3)$ & \\
\hline \multirow{2}{*}{ Smoking } & Yes & $14(16.3)$ & $21(24.4)$ & \multirow{2}{*}{0.18} \\
\hline & No & $72(83.7)$ & $65(75.6)$ & \\
\hline
\end{tabular}

${ }^{\mathrm{a}}$ Values are expressed as No. (\%).

Table 2. Comparing the Study Groups Regarding the Mean Scores of QOL and Its Dimensions

\begin{tabular}{l|c|c|c|c}
\hline QOL Dimensions & Time & Experimental Group & Control Group & P Value (The Independent-Sample T-Test) \\
\hline \multirow{2}{*}{$\begin{array}{l}\text { Activity limitation } \\
\text { Emotional function }\end{array}$} & Before & $14.25 \pm 3.45$ & $14.96 \pm 3.13$ & \multicolumn{1}{c}{0.16} \\
\cline { 2 - 5 } & After & $8.48 \pm 2.68$ & $14.90 \pm 3.13$ & $33.03 \pm 6.54$ \\
\hline \multirow{2}{*}{ Total QOL } & Before & $31.61 \pm 7.17$ & $32.86 \pm 6.60$ & 0.001 \\
\cline { 2 - 5 } & After & $18.90 \pm 5.61$ & $47.99 \pm 9.67$ & $<0.001$ \\
\hline
\end{tabular}

Table 3. Pretest-Posttest Comparisons of QOL Scores in Both Groups

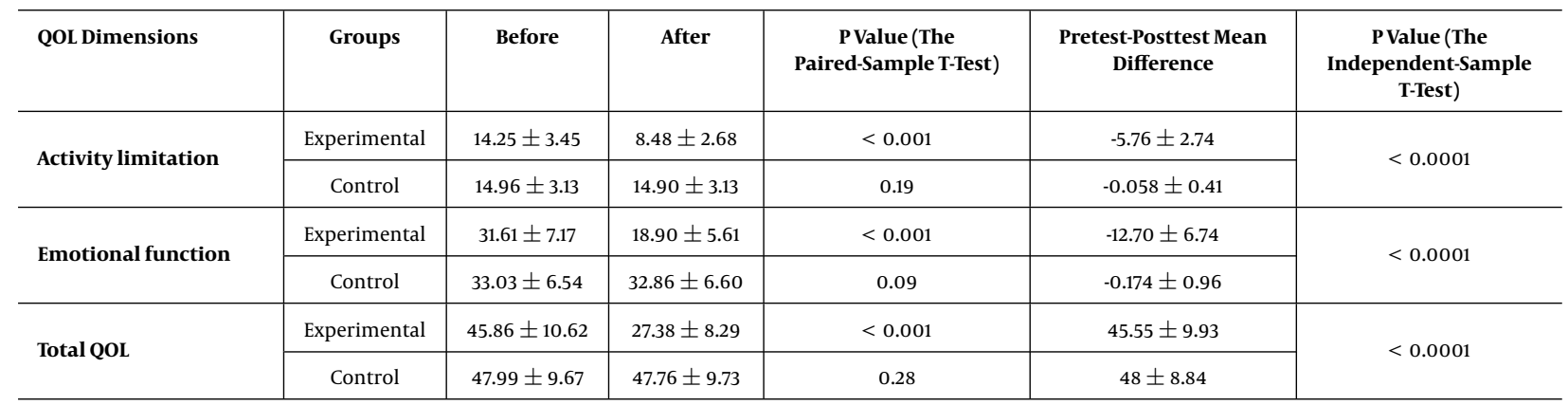

the FCEM can help enhance mothers' independence in providing patient care and improve their QOL (1). Karimi Monaghi et al. (2009) also found the FCEM effective in improving QOL among patients with multiple sclerosis and noted that this model has preferences over other programs and models due to its cost-effectiveness, simplicity, and familycenteredness (20).

Walker et al. (2008) carried out a study in Maryland to examine the effects of school-based training on the QOL of the parents of school-age asthmatic children. Their 
findings indicated that their intervention significantly improved parents' knowledge, self-reliance, self-efficacy, endurance, confidence in healthcare system, ability to communicate with healthcare professionals, and QOL (8). Although most of the previous studies indicated the effectiveness of family-centered interventions in improving family caregivers' QOL, some studies reported that these interventions had no significant effects on QOL. For example, Cano-Garcinuno et al. (2007) found that group education of asthmatic children and their parents was effective in improving the children's pulmonary function and self-efficacy and reducing the number of their absences from school; but it had no significant effects on parents' QOL (21). Besides, Shahriari et al. (2005) reported that their educational intervention was effective in improving physical QOL and had no significant effects on mental QOL (22). These conflicting findings may be attributed to the fact that the employed interventions had been singlecomponent in these two studies. Such interventions usually produce short-term effects. However, interventions which are developed based on the FCEM incorporate multiple strategies such as education, group discussion, role playing, and educational partnership. Masoodi et al. (2013) also found the FCEM effective in improving the QOL of the family caregivers of patients with multiple sclerosis (23). Given the significant role of mothers in families and the significant effects of interactive relationships between family members, it is expected that the empowerment of an active family member would result in the empowerment of the whole family system. Family empowerment in turn enhances family members' self-efficacy in care giving to chronically-ill members and improves their health.

Another aim of the study was to examine the relationship of QOL with demographic characteristics in both groups. The findings revealed that mothers' QOL was significantly correlated with their age, place of residence, absence from work, and family size as well as their children's type of asthma, medical visit, emergency department attendance, and hospitalization $(\mathrm{P}<0.05)$. Our findings showed that mothers' QOL was significantly correlated with their place of residence so much so that mothers who lived in urban areas had higher QOL than others. Alavi et al. (2007) also reported that villagers had lower QOL. This finding can be attributed to rural dwellers' more limited access to healthcare facilities (24). Most of our participants were city dwellers. The reason behind this finding may be that rural dwellers who suffer from asthma usually visit doctors in their villages and refer to urban healthcare centers only when their illness and symptoms worsen and they need hospitalization. According to Horner (2006), in rural areas, families have more limited access to healthcare and social resources and thus, they need to travel long distances in order to get access to advanced medical and care services (25). Such barriers require families to manage asthma at homes. Indeed, our findings denoted that these barriers negatively affect the level of medical and care services received by rural families. Horner and Fouladi (2003) also reported that only half of the children who live in rural areas refer to specialists or emergency departments for receiving asthma care (26). Moreover, CarvajalUruena (2005) found that children who lived in cities obtained higher QOL scores than children who lived in villages probably due to their easier access to quality medical services. They also noted that asthma is more prevalent in urban areas (27). Butz et al. (2005) reported that in rural areas, children face different risk factors, which can make asthma management more difficult (28).

We also found that mothers' age significantly affected their QOL. In other words, younger mothers had better QOL. This finding may be due to younger mothers' wider use of educational programs broadcasted by media or their higher motivation for participating in educational programs.

Our findings also showed that mothers' absence from work affected their QOL. In other words, mothers with more absences from work had lower QOL. When an asthma attack happens or when symptoms worsen, a mother needs to leave her work and take her child to doctor or hospital. Similarly, when an asthma attack happens at midnight, a mother needs to stay awake for hours and hence, she may not be able to attend work the next day or may be too tired to work productively, resulting probably in employment loss. These factors can negatively affect QOL.

Most of the participating mothers had two children. Small family size enables parents to spend more time on giving care to their ill children. Our findings revealed that the smaller the family size was, the better QOL the mothers had. This finding may be due to the fact that in bigger families, mothers usually have more professional or family tasks and thus, have more limited time for participating in educational programs on their children's illnesses.

We also found that the numbers of medical visits, emergency department attendances, and hospitalizations affected mothers' QOL so much so that the bigger the numbers, the lower the QOL. Such visits and hospitalizations necessitate spending a great deal of time and energy that negatively affect mothers' mental health and psychological well-being. Most participants noted that acute symptoms of asthma appear mainly at night. Moreover, they had referred to their doctors more than three times during the last year before the study. All these findings show that many factors can contribute to the QOL of the mothers of asthmatic children. 


\subsection{Conclusions}

The findings of the study show that the FCEM improves the QOL of the mothers of asthmatic children both in the activity limitation and emotional function domains. Given the significant role of mothers in giving care to their ill children, nurses are recommended to use the FCEM to encourage mothers' active participation in care giving to their children and also to improve the QOL of both ill children and their mothers.

\section{Acknowledgments}

The present manuscript emanated from a research project approved by the research administration of Kerman University of Medical Sciences, Kerman, Iran, with the code of 278.90. The authors would like to thank the administrators of Afzalipour and Bahonar hospitals, Kerman, Iran, who supported the study as well as the participants and their families.

\section{References}

1. Hasankhani H, Gharemohammadlu R, Esmaeily M. Relation of patients self-efficacy with control of asthma symptoms. J Gorgan Univ Med Sci. 2013;15(2):70-6.

2. Teymouri F, Alhani F, Kazemnejad A. The effect of family-centered empowerment model on the Quality of life of school-age asthma children. J Hamadan Nurs Midwifery Faculty. 2011;22(3):5-14.

3. Dean BB, Calimlim BC, Sacco P, Aguilar D, Maykut R, Tinkelman D. Uncontrolled asthma: assessing quality of life and productivity of children and their caregivers using a cross-sectional Internet-based survey. Health Qual Life Outcomes. 2010;8:96. doi: 10.1186/1477-7525-8-96. [PubMed: 20825674]

4. Faye AD, Gawande S, Tadke R, Kirpekar VC, Bhave SH, Pakhare AP, et al. Do Panic Symptoms Affect the Quality of Life and Add to the Disability in Patients with Bronchial Asthma?. Psychiatry J. 2015;2015:608351. doi: 10.1155/2015/608351. [PubMed: 26425540].

5. Elliott TR, Berry JW, Grant JS. Problem-solving training for family caregivers of women with disabilities: a randomized clinical trial. Behav Res Ther. 2009;47(7):548-58. doi:10.1016/j.brat.2009.03.006. [PubMed 19361781].

6. Varni JW, Limbers CA, Burwinkle TM. How young can children reliably and validly self-report their health-related quality of life?: an analysis of 8,591 children across age subgroups with the PedsQL 4.0 Generic Core Scales. Health Qual Life Outcomes. 2007;5:1. doi: 10.1186/1477-75255-1. [PubMed: 17201920].

7. Everhart RS, Fiese BH, Smyth JM. A cumulative risk model predicting caregiver quality of life in pediatric asthma. J Pediatr Psychol. 2008;33(8):809-18. doi:10.1093/jpepsy/jsn028. [PubMed: 18356183].

8. Walker J, Winkelstein M, Land C, Lewis-Boyer L, Quartey R, Pham L, et al. Factors that influence quality of life in rural children with asthma and their parents. J Pediatr Health Care. 2008;22(6):343-50. doi: 10.1016/j.pedhc.2007.07.007. [PubMed: 18971080].

9. VanLeit B, Crowe TK. Outcomes of an occupational therapy program for mothers of children with disabilities: impact on satisfaction with time use and occupational performance. Am J Occup Ther 2002;56(4):402-10. [PubMed: 12125829].

10. Klassen AF, Raina P, McIntosh C, Sung L, Klaassen RJ, O'Donnell M, et al. Parents of children with cancer: which factors explain differences in health-related quality of life. Int J Cancer. 2011;129(5):1190-8. doi: 10.1002/ijc.25737. [PubMed: 21064097].
11. Grineski S. Coping with asthma in the central city: parental experiences with children's health care. J Health Care Poor Underserved. 2008;19(1):227-36. doi: 10.1353/hpu.2008.0025. [PubMed: 18263998].

12. Himes BE, Lasky-Su J, Wu AC, Wilk JB, Hunninghake GM, Klanderman $B$, et al. Asthma-susceptibility variants identified using probands in case-control and family-based analyses. BMC Med Genet. 2010;11:122. doi: 10.1186/1471-2350-11-122. [PubMed: 20698975].

13. Lefebvre H, Levert MJ, Pelchat D, Lepage JG. Nature, sources, and impact of information on the adjustment of family caregivers: a pilot project. Can J Nurs Res. 2008;40(1):143-60. [PubMed:18459277].

14. Yee $A B$, Fagnano M, Halterman JS. Preventive asthma care delivery in the primary care office: missed opportunities for children with persistent asthma symptoms. Acad Pediatr. 2013;13(2):98-104. doi: 10.1016/j.acap.2012.10.009. [PubMed: 23294977].

15. Vahedian Azimi A, Alhani F, Ahmadi F, Kazemnejad A. Effect of familycentered empowerment model on the life style of myocardial infarction patients. J Crit Care Nurs. 2010;2(4):1-2.

16. Moridi G, Khaledi SH, Valiee S, Shikhzakariaei N, Omati A. Comparison view point of children and their mothers about quality of life children with asthma. Iran J Nurs Res. 2013;8(3):65-72.

17. Parvizi S, Ghasemzadeh kakroudi F, Seyed Fatemi N, Naseri F. Social factors contributing in women health in Tehran city: A qualitative study. Iran J Nurs Res. 2009;4(15):6-15.

18. Anderson RM, Funnell MM. Compliance and adherence are dysfunctional concepts in diabetes care. Diabetes Educ. 2000;26(4):597-604.

19. Welch JL, Austin JK. Stressors, coping and depression in haemodialysis patients. J Adv Nurs. 2001;33(2):200-7.

20. Karimi Monaghi H, Haresabadi M, Froghipor M, Zarifnegad GH, Mazlom SR, Alhani F. The effect of family-centered empowerment model on the quality of life of patient with multiple sclerosis. J Mashhad Sch Nurs Midwifery. 2009;9(22):82-93.

21. Cano-Garcinuno A, Diaz-Vazquez C, Carvajal-Urue-a I, Praena-Crespo M, Gatti-Vi-oly A, Garcia-Guerra I. Group Education On Asthma Children and Caregivers: a Randomized, Controlled Trial Addressing Effects on Morbidity and Quality of Life. J Investig Allergol Clin Immunol. 2007;17(4):216-26.

22. Shahriari M, Jalalvandi F, Yousefi H, Tavkol K, Saneei H. The effect of a self-care program on the quality of life of patients with permanent pacemaker. Iran J Med Educ. 2005;5(1):45-52.

23. Masoodi R, Alhani F, Rabiei L, Majdinasab N, Moghaddasi J, Esmaeili SA, et al. The effect of family-centered empowerment model on quality of life and self efficacy of multiple sclerosis patients family care givers. Iran J Nurs Res. 2013;7(27):32-43.

24. Alavi A, Parvin N, Kheyri S, Hamidizadeh S, Tahmasebi S. Comparison of perspective of children with major thalassemia and their parents about their quality of life in Shahrekord. J Shahrekord Uuniv Med Sci. 2007;8(4):35-41.

25. Horner SD. Home visiting for intervention delivery to improve rural family asthma management. J Community Health Nurs. 2006;23(4):213-23. doi: 10.1207/s15327655jchn2304_2. [PubMed: 17064231].

26. Horner SD, Fouladi RT. Home asthma management for rural families. J Spec Pediatr Nurs. 2003;8(2):52-61. [PubMed:12875173].

27. Carvajal-Uruena I, Garcia-Marcos L, Busquets-Monge R, Suarez-Varela MM, de Andoin NG, Batlles-Garrido J, et al. Variaciones geográficas en la prevalencia de síntomas de asma en los niños y adolescentes españoles. International Study of Asthma and Allergies in Childhood (ISAAC) fase III España.Archivos de Bronconeumología. 2005;41(12):65966.

28. Butz A, Pham L, Lewis L, Lewis C, Hill K, Walker J, et al. Rural children with asthma: impact of a parent and child asthma education program. I Asthma. 2005;42(10):813-21. doi: 10.1080/02770900500369850. [PubMed:16393717] 